\title{
La libertad garantizada por los derechos fundamentales en la época del terrorismo desde la perspectiva alemana
}

\section{Analysis of Liberty, as it is Guaranteed by the German Constitution, in Times of Terrorism}

Por Martín Ibler *

Fecha de recepción: 16 de abril de 2008

Fecha de aprobación: 5 de mayo de 2008

\section{Resumen}

En Alemania la Ley Fundamental ha otorgado importantes mecanismos de protección a la libertad de las personas; este derecho ha sido acompañado de mecanismos para su cumplimiento como de instituciones que cuidan y protegen la libertad de las personas en sus diferentes manifestaciones. Sin embrago, la dinámica reciente de seguridad y lucha contra el terrorismo están llevando a nuevas políticas que terminan por afectar y debilitar el derecho a la libertad. El objetivo del presente artículo es analizar la libertad a luz de los nuevos patrones de seguridad y lucha contra el terrorismo que se desarrolla en Alemania.

\section{Palabras clave}

Libertad, terrorismo, seguridad, derecho penal del enemigo.

Profesor y exdecano de la Facultad de Jurisprudencia de la Universidad de Konstanz (Alemania). Profesor de la Maestría en Derecho Público de la Universidad Santo Tomás en convenio con la Universidad de Kotanz. 


\begin{abstract}
In Germany, the Constitution grants important mechanisms and institutions to protect the liberty of its citizens in all its different manifestations. However, the recent dynamics of securities within the framework of the war against terrorism has led to new politics which tend to affect and weaken the right to liberty. The objective of the present article is to analyze liberty in the light of the war against terrorism and the new security patterns which arise in Germany.
\end{abstract}

\title{
Key words
}

Liberty, terrorism, security, penal law of the enemy.

\section{PRINCIPIOS Y DESAFÍOS}

Gracias a la Ley Fundamental de 1949, la protección de la libertad de las personas es tan fuerte como nunca antes en la historia alemana. Ello tiene muchas razones, tres de las cuales quiero resaltar ante ustedes ${ }^{1}$ :

- La primera razón es la consecución de un catálogo de Derechos Fundamentales en la cima de la Ley Fundamental; este catálogo abarca la mayoría de las formas de manifestación de la libertad, como por ejemplo, el derecho a la vida y a la integridad corporal, la libertad de desplazamiento, la libertad de opinión, prensa y artística, la libertad religiosa, y la libertad general de acción. Con eso, el catálogo de Derechos Fundamentales es objetivo y realista, pues, por un lado, no contiene compromisos de libertad que el Estado no puede cumplir -como sucedería con un derecho fundamental a un puesto de trabajo, pero también con un Derecho Fundamental a una seguridad completa. Por otro lado, el catálogo admite una interpretación de los derechos fundamentales, con la cual se

$1 \quad$ Otras razones para una fuerte protección de la libertad en Alemania son, por ejemplo, la especial separación de poderes alcanzada a través del principio del estado federal, la garantía de los derechos fundamentales también en las constituciones de los estados federados, complementada en algunos de ellos con la posibilidad de un recurso de amparo ante los tribunales constitucionales de los estados federados. pueden incluir en su protección contenidos de libertad no mencionados expresamente, como sucedió en la famosa sentencia sobre el censo de la población (Tribunal Constitucional Federal, s.f., pp. 1-ss), en la cual el Tribunal Constitucional Federal desarrolló el derecho a la autodeterminación informativa, con base en el derecho fundamental al libre desarrollo de la personalidad (art. 2 Abs. 1 LF), en conexión con la garantía de la dignidad humana. (art. 1 inciso 1 LF).

- La segunda razón deriva de la fuerte protección actual a los Derechos Fundamentales, por cuanto son concebidos como derecho vinculante inmediato para todas las ramas del poder público. Esta vinculación inmediata está dispuesta expresamente en el art. 1 inciso 3 LF. y constituye un alejamiento de la situación jurídica existente bajo la Constitución de la República de Weimar de 1919 y una reacción frente a las experiencias de la dictadura nacional-socialista entre 1933 y 1945. En consecuencia, no se puede ocultar que está expresa la vinculación que se le ha fijado al poder público, los cual en Alemania hace ver los Derechos Fundamentales de manera diferente a lo que ocurre en muchos otros Estados. En estos Estados sólo son válidos como derechos (de defensa) frente al Estado, lo cual excluye una vinculación inmediata de los ciudadanos con los Derechos Fundamentales. Esto conduce a ciertas dificultades dogmáticas, puesto que, inicialmente, el término "efecto jurídico 
mediato de los derechos fundamentales entre particulares" bastaba. Hoy en día, también se puede encontrar la construcción de la dogmática constitucional de los así llamados deberes de protección del Estado, sin embargo, ésta es pertinente a la hora de ejercer una defensa frente a amenazas terroristas (Callies, 2006, p. 325), en este contexto, porque el Estado debe proteger los derechos fundamentales cuando se presenten ataques de terceros privados.

- Una tercera razón de importancia para la efectividad de los derechos fundamentales de la Ley Fundamental alemana es la protección de dichos derechos a través de jueces independientes. Ante todo, dicha protección se alcanza gracias a dos decisiones constitucionales: por el derecho fundamental a la protección judicial efectiva, como clave y corona del catálogo de derechos fundamentales (art. 19 inc. 4 LF) y por la creación del Tribunal Constitucional Federal, con su competencia para decidir sobre el recurso de amparo constitucional. La protección de los derechos fundamentales, por parte de tribunales ordinarios y del Tribunal Constitucional Federal, asegura la libertad garantizada por los derechos fundamentales, una libertad de las personas que es garantizada de manera ejemplar, incluso, en una comparación con el resto del mundo ${ }^{2}$. A través de la superioridad jerárquica del Tribunal Constitucional Federal sobre los tribunales ordinarios, que se expresa, ante todo, en el efecto vinculante de sus decisiones (Ley del Tribunal Federal Constitucional, s.f., § 31), el ordenamiento jurídico alemán consigue un fundamento para una dogmática de los Derechos Fundamentales unitaria, por ende, efectiva.

A pesar de esta fuerte protección a los derechos fundamentales, la libertad de las personas cada

2 Sobre las desventajas de la falta de un recurso de amparo constitucional en el derecho constitucional turco consultar: Fazil Sağlam (2006, pp. 179 y197-ss.) día es amenazada de varias maneras. Por ejemplo, recientemente ha aparecido un nuevo peligro: el llamado terrorismo islámico (Diwell, 2005, pp. 11 y ss.), que amenaza a las personas y provoca con ello que el Estado reaccione o también que sobrereaccione. Estas nuevas formas criminales se diferencian claramente del terrorismo criminal alemán de los años setenta (Diwell, 2005, pp. 15 y ss.), es decir, no limita el número de los posibles autores a un círculo comparativamente pequeño, claramente determinable y en ocasiones conocido de terroristas, tampoco son evidentes los objetivos, la forma y la dimensión de los posibles atentados. Ahora bien, no quiero juzgar si estas nuevas formas de criminalidad se diferencian del terrorismo de ETA en España, de los norirlandeses del IRA, del PKK kurdo, o de las FARC en Colombia, puesto que el objetivo del presente artículo es concentrarse en la amenaza para Alemania y para el Derecho Nacional.

Para Alemania, esta nueva situación de peligro provoca que el Estado, busque y adopte preventivamente "nuevas" medidas de seguridad. Con ellas se pretende proteger a las potenciales víctimas de ataques terroristas, pero, a la vez, también se puede reducir la libertad garantizada por los Derechos Fundamentales de las personas que se protegen. Por ejemplo, desde los recientemente frustrados atentados contra dos trenes regionales de la Empresa de Trenes Alemanes con bombas escondidas en el equipaje, se han aumentado los casos en los que la policía -aun en pequeños lugares- bloquea sectores completos de la ciudad durante horas pico de tráfico vehicular, porque se han encontrado bolsos, maletas o equipaje sin dueño. Éstos son revisados exhaustivamente por especialistas en explosivos, hasta que finalmente se constata que se trata de equipaje o mochilas olvidadas (Terrorangst am Busbahnhof, 25 de octubre de 2006, pp. 1-27). Con lo anterior se puede ver que la libertad garantizada por los derechos fundamentales de las personas protegidas del terrorismo está más en primer plano. Sin embargo, 
solamente me voy a ocupar de la protección de los derechos fundamentales de los verdaderos criminales terroristas marginalmente ${ }^{3}$.

El objetivo del presente artículo es examinar la libertad garantizada por los derechos fundamentales a la luz de "la época del terrorismo"; esto, por supuesto, sugiere que esta libertad ha entrado en la actualidad en una fase especial, a saber: se encuentra ante un desafío de época. Los devastadores atentados de los últimos años, que comenzaron con el atentado al World Trade Center en Nueva York (11 de septiembre de 2001), seguido por los perpetrados en Madrid (11 de marzo de 2004) y en Londres (7 de julio de 2005), parecen confirmar esta visión (Frankfurter Allgemeine, 23 de octubre de 2006, p. 11).

El mundo occidental reaccionó a estos ataques potenciando la seguridad, no obstante, esta fórmula ha repercutido en la libertad del ciudadano inocente, ya que se pueden ver afectados sus derechos fundamentales. Además, fue aprobada y aceptada muy rápido, como si fuera una palabra mágica (Hetzer, 2005, p. 132; Callies, 2002, pp. 1-2).

En Alemania también han aumentado las leyes que, para proteger al ciudadano, al mismo tiempo posibilitan y hacen temer una desprivatización de las personas por medio de su vigilancia en cualquier momento. Sin embargo, hay garantías para que esto no suceda, como es el derecho a la autodeterminación informativa, el cual protege los datos las personas cuando éstas sean investigadas, es decir, son guardados y sólo son utilizados nuevamente si así se requiere. De igual forma, el individuo debe poder determinar quién, cuándo y qué se sabe sobre él (Tribunal Constitucional Federal, s.f., t. 65, pp.1-43; t. 80, pp. 367-373, t. 103, pp. 21-33) y sus datos sólo pueden ser recabados

3 Sobre este tema se puede consultar: Michael Ch. Jakobs (2006, pp. 83 y ss.); Winfried Bausback (2005, pp. 418 y ss.). excepcionalmente y sólo para determinados fines, previstos en la ley. Cuando esto sucede, únicamente pueden ser utilizados para esos fines (Tribunal Constitucional Federal, s.f., t. 65, pp. 1-46).

En 1983, el Tribunal Constitucional Federal basó el derecho a la autodeterminación informativa en la garantía a la dignidad humana (t. 65, pp. 1 y ss.). Su importancia fue ampliamente respetada y reconocida por largo tiempo; no obstante, hoy en día, no es así, por lo tanto, la protección de los datos personas se debilita sucesivamente. Un ejemplo de esa tendencia son las llamadas nuevas leyes de libertad de información de la Federación y de algunos Estados Federados (Ibler, 2002, pp. 405 y ss.). Estas leyes garantizan, supuestamente como apoyos democráticos y para fortalecer la libertad de información, pretensiones de acceso a información que no están conectadas a ninguna clase de condiciones especiales (art.1 Inc. 1 frase 1 Ley de libertad de información).

Por medio de estas leyes las autoridades tienen permitido revelar datos confidenciales, bajo ciertas circunstancias, si el interés de su publicación prevalece para la generalidad sobre el interés de su confidencialidad (Ley de libertad de información, $§ 5$ pár. 1 frase 1). Es así como la protección de datos se vuelve susceptible de ponderación y de que se puedan socavar los datos almacenados; en consecuencia, es indiferente que las autoridades administrativas recaben datos sólo para determinados fines administrativos, si a través de pretensiones de acceso a información incondicionadas, cualquiera se puede acercar a ellos, sin ningún propósito establecido. Como se puede ver, las nuevas leyes debilitan la protección a los derechos fundamentales.

Una de las formas en que no se protegen los derechos de las personas está en el hecho de que las entidades encargadas de la protección de datos de la Federación y de algunos Estados Federados también son las encargadas velar por la ley de la 
libertad de información (Tribunal Constitucional Federal, s.f. § 12 párr. 2 IFG; Ibler, 2002, pp. 415 y ss.). Por lo tanto, no puede haber una protección como tal, ya que los intereses son opuestos, en consecuencia, la protección de datos y la revelación de información deberían estar representados por órganos estatales diferentes, puesto que, en caso de conflicto, podrían llegar a un acuerdo, o lo que sería aún mejor, se podría dejar que un tercer órgano decidiera.

Otro ejemplo reciente de una transmisión simplificada de los datos personales, y con ello un debilitamiento del derecho fundamental de la autodeterminación informativa, se puede observar en la revelación de los datos de pasajeros de vuelos con destino a Estados Unidos ${ }^{4}$. Con el objetivo subyacente de "luchar contra el terrorismo" se aclara -de manera similar a como sucede en el caso de la "lucha contra el crimen organizado" - la relación de tensión existente entre la seguridad y la libertad garantizada por los derechos fundamentales.

No existe libertad sin seguridad, pero a partir de un cierto grado de seguridad, se elimina la libertad. Lo ideal sería una solución que materializara ampliamente seguridad y libertad. Sin embargo, este deseo se parece a una cuadratura del círculo; no se sabe cómo sería tal Estado, ni cómo podría ser alcanzado. Entonces, se vería un proceso de aprendizaje ensayo-error ("trial and error") $)^{5} y$, por ende, algunas tentativas de solución. En este proceso de aprendizaje de ensayo-error, se pueden probar y desechar posibilidades de solución,

4 Decisión 2006/729/GASP/JI del Consejo del 16. de octubre 2006 sobre la firma. Se llegó a un acuerdo entre los Estados Unidos de América y la Unión Europea enviar los datos de los pasajeros y su traslado por las compañías aéreas al United States Department of Homeland Security.

5 Bajo ensayo y error entiende el psicólogo americano Edward Thorndike (1874 -1949) un método de solución de problemas, con el que se prueban métodos admisibles de solución hasta que se consiga la solución (resultado) deseado. Con eso se asume conscientemente la posibilidad de fracasos (Anderson, 2000, pp. 12 y ss.). hasta que sea encontrada la adecuada. Si esto se trasladara al poder público alemán, significa que el Estado intenta combatir el terrorismo con nuevos métodos, teniendo en cuenta que sólo después será frenado por el Tribunal Constitucional Federal. El legislador no debería desechar la competencia del Tribunal Constitucional Federal (Pestalozza, 1991, § 17 II 2, pp. 236 y ss.) y así tener un concepto previo $^{6}$, como sucede en tribunales constitucionales de otros países (Schmidt, 2006, pp. 163 y ss.) ${ }^{7}$. Ahora bien, ya se han superado algunos intentos de solución por parte del legislativo, del ejecutivo y del gobierno, en parte con la ayuda posterior del Tribunal Federal Constitucional y con diversos resultados, pero aún quedan discusiones político jurídicas sobre otros intentos de solución.

Los intentos de solución del legislador alemán se pueden esquematizar bajo palabras clave como, por ejemplo: "punibilidad de la formación de organizaciones terroristas" (§ 129a Código Penal); "derribo de aviones de pasajeros según la Ley de Seguridad Aérea" (el anterior artículo 14 párr. 3 de la Ley de Seguridad Aérea); "aumento de la admisión de la investigación policial preliminar independiente de sospecha por medio, por ejemplo, de la recopilación computarizada de datos personales con fines criminológicos" (§ 40 inc. 1 Ley de Policía B.-W. $)^{8}$; "construcción de sistemas de información preventiva"; "videovigilancia de lugares públicos" (§ 21 Abs. 3 Ley de Policía B.-W.); “Ley de lucha contra el terrorismo" (Boletín oficial, 2002, tomo I, , p. 361), y la igualmente planeada, ley complementaria de lucha contra el terrorismo -que, entre otras cosas, faculta a la Oficina de Protección Constitucional, al Servicio de la Defensa Militar-y

6 Cfr. §97 Ley del Tribunal Federal Constitucional, antigua versión, eliminado por la Ley para la reforma de la BVerfGG del 21. 7. 1956 (BGBI. I p. 662).

7 Por ejemplo: Estonia (§§ 2, 7 de la ley sobre el proceso de vigilancia constitucional, Staatsanzeiger [Riigi Teataja RT I 2005 68, 524]) Finlandia, Liechtenstein y Hungría.

8 Se puede ampliar la información en: Volkmar Götz (2001, número marginal 533); Thomas Würtenberger und Dirk Heckmann, (2005, número marginal 671). 
al Servicio Federal de Inteligencia, para requerir información a las compañías aéreas y a las autoridades de matriculación de vehículos ${ }^{9}$. Además, se deben nombrar nuevos métodos de investigación, como la "interceptación de mensajes de texto de teléfonos celulares" (Tribunal Constitucional Federal, 2006) y la vigilancia acústica de espacios residenciales (Tribunal Constitucional Federal, s.f., t. 109, pp. 279 y ss.), o la construcción de una red federal de datos utilizables frente el terrorismo, recientemente aprobada por el Bundestag ${ }^{10}$.

Otros intentos de solución que nos amenazan en la lucha contra el terrorismo son: la discusión en materia de Derecho Penal sobre el llamado "Derecho penal del enemigo", que implica renunciar a conquistas del Estado de Derecho, como las garantías procesales en el procedimiento penal, y con ello, a la garantía de libertad para los enemigos del Estado (Jakobs, 2004, pp. 88 y ss.; Bung, 2006, pp. 63 y ss.; Sinn, 2006, pp. 107 y ss.). Personalmente, no comparto otra propuesta, en la cual un Estado, dispuesto a una comunicación razonablemente jurídica, en principio, no puede dialogar con terroristas, de tal manera que al Estado de Derecho sólo le quedaría la aplicación de la violencia física (Roellecke, 2006, pp. 265-268). Con esto, se cedería la comunicación a los Estados Unidos y a otros Estados. Ambas propuestas también toman demasiado en serio a los terroristas y a la seguridad, y a la vez descuidan la libertad garantizada por los derechos fundamentales de todos los demás.

La actual discusión político-jurídica sobre la libertad garantizada por los derechos fundamentales y el terrorismo se desarrolla en torno a otras preguntas.

9 http://www.bmi.bund.de/Internet/Content/Common/Anlagen/ Nachrichten/Pressemitteilungen/2006/07/ Informatioen_zum_Terrorismusaenderungsgesetz, templateld=raw, property=publicationFile.pdf/

10 Frankfurter Allgemeine Zeitung, 21 de octubre de 2006; Bundestags-Drucksache (BT-Drs.) 16/2950 del 16 de octubre de 2006 y BT-Drs. 16/3642 del 29 de noviembre de 2006.
Entre ellas se encuentran: ¿los organismos oficiales tienen permitido utilizar informaciones de servicio secreto, que han sido obtenidas por otros Estados, que probablemente han empleado la tortura para conseguirlas? ¿El deber de protección del Estado requiere para sus ciudadanos que organismos alemanes también valoren tales informaciones? (Hetzer, 2006, pp. 148-150.

Asimismo, se discute, desde el punto de vista jurídico y político, si se debe calificar al terrorismo internacional, sobre todo el islamista, "solamente" como criminalidad, o si debe ser considerado como estrategia ("asimétrica") de guerra. Es decir, si debe ser combatido por la policía y la persecución penal, o si debe serlo por el ejército en un eventual nuevo caso de defensa (Hetzar, 2007, pp. 428 y ss.; Timm, 2006, pp. 146 y ss.; Wielfelspütz, 2006, pp. 41-42).

Desde esta perspectiva, en este momento se está elaborando un plan en el Ministro del Interior alemán para los así llamados "registros en línea de computadores" (Online-Durchsuchung); quien sea sospechoso de terrorismo, recibirá un correo electrónico por parte de la Oficina federal de investigación criminal con un falso remitente, por ejemplo de la Oficina de la juventud, de la Oficina de la asistencia social o de la Oficina de hacienda. Este correo electrónico, supuestamente inofensivo, es en realidad un "Caballo de Troya"; si se abre, instalará en el computador un software, con el cual la Oficina federal de investigación criminal puede leer por Internet todos los datos de ese computador (Süddeutsche Zeitung, 31 de agosto de 2007, p. 6).

El llamado a la protección del ciudadano frente a atentados terroristas también se intenta aplicar en el del Derecho Urbanístico. Ya se reclaman leyes para mejorar la seguridad, las cuales están apoyadas en el deber constitucional de protección del Estado (del Art. 2 inc. 2 frase 1 y Art. 14 inc. 1 Ley Fundamental), por medio de las cuales un vecino 
puede oponerse a la licencia de construcción de embajadas y consulados amenazados por el terrorismo, o como mínimo, puede exigir que se tomen las medidas necesarias de precaución (Michaela Wittinger, 2006, pp. 17-22).

Tanto los intentos de solución del ejecutivo y del gobierno, como la falta de esfuerzos de solución por omisión amenazan la libertad, un ejemplo es el caso concreto de cuando el gobierno y los organismos de seguridad no cumplen suficientemente las leyes, con las cuales el legislador ha querido controlar la libertad garantizada por los derechos fundamentales y la seguridad. Actualmente se puede observar el reproche contra el gobierno actual y sus predecesores, así como contra los organismos de seguridad, por haber colaborado en el secuestro de un ciudadano alemán con ascendencia libanesa por el servicio secreto americano, CIA (caso El Masri). Otro caso actual es el de un hombre nacido en Alemania, así como su familia, pero casado en Turquía: fue arrestado en Afganistán por el ejército de los Estados Unidos, encarcelado y probablemente torturado por años en Guantánamo, Cuba (Christen, 19 de octubre de 2006, p. 3).

Menos espectacular, pero mejor para la observación pública, y más interesante para la libertad garantizada por los derechos fundamentales, desde el aspecto de la protección de datos son los intentos del ejecutivo de reaccionar ante nuevas situaciones de peligro sin modificaciones legislativas, a través de la formación de nuevos grupos de trabajo estatales. Un ejemplo proveniente de Baviera es el grupo creado en otoño de 2004 BIRGiT (Identificación y reducción acelerada de peligros en el área del terrorismo/extremismo islamista) (Buggisch \&Walter Knorz, 2006, pp. 226-230). Además, debido al incremento en la internacionalización de la criminalidad -especialmente terrorismo y crimen organizado-, en 1995 fue creada la Oficina Federal de Investigación Criminal, una nueva división IK (Coordinación Internacional, por sus siglas en alemán) con 265 funcionarios. Según una formulación usual del alemán tecnocrático criminológico, esta oficina debe, entre otras cosas, a través de "Conexiones metódicamente realizadas de informaciones (parciales), extraer consecuencias sobre posibles repercusiones criminológicas futuras" (Kubica, 2006, pp. 167 y ss.).

Las propuestas de solución, mencionadas a modo de palabras clave, y otras futuras para la superación de amenazas terroristas con sucesos más o menos espectaculares, como los secuestros mencionados, ponen a prueba, una y otra vez, la protección de la libertad garantizada por los derechos fundamentales.

\section{DOGMÁTICA DE LOS DERECHOS FUNDAMENTALES EN LA ÉPOCA DEL TERRORISMO. CONTRIBUCIONES JURÍDICAS A UNA LUCHA CONTRA LA CRIMINALIDAD TERRORISTA QUE ASEGURE LOS DERECHOS FUNDAMENTALES}

A la pregunta cómo la seguridad y la libertad pueden ser garantizadas suficientemente en el Estado de Derecho, el cual por su naturaleza no puede responder breve ni completamente, quiero señalar algunos puntos de vista, desde los cuales se pueden observar las contribuciones jurídicas a una solución. En especial, quisiera realzar algunos mecanismos concretos con los que el Derecho Constitucional alemán, en vista de la amenaza terrorista, puede proteger la libertad garantizada por los derechos fundamentales de las personas a través de la organización estatal y de la dogmática.

La libertad garantizada por los derechos fundamentales se puede asegurar de manera efectiva, con ayuda de las tres precauciones inicialmente mencionadas (1. catálogo de derechos fundamentales aplicable; 2 . vinculación inmediata de todo el 
poder público a los derechos fundamentales, y 3 . un contundente Tribunal Constitucional Federal). Esto ha sido confirmado por las recientes decisiones del Tribunal Constitucional sobre la ley de seguridad aérea (Tribunal Constitucional Federal, 15 de febrero de 2006, pp. 751 y ss.) y sobre el control computarizado de datos personales (Rasterfahndung) (Tribunal Constitucional Federal, 4 de abril de 2006, pp. 1939 y ss). También las decisiones del Tribunal Constitucional Federal sobre la admisibilidad de la selección de datos de teléfonos celulares (Tribunal Constitucional Federal, 2 de marzo de 2006, pp. 976 y ss.), sobre la vigilancia secreta a gran escala (Tribunal Constitucional Federal, s.f., pp. 279 y ss.) y sobre la orden de detención europea (Tribunal Constitucional Federal, s.f., tomo 113, pp. 273 y ss.) lo documentan. Por último, las sentencias nombradas no prevén específicamente la amenaza terrorista, pero ponen límites a las medidas de investigación que, justamente, pueden ser utilizadas en la lucha contra el terrorismo internacional.

El Estado de Derecho y sus manifestaciones legales son mecanismos importantes para la protección de la libertad garantizada por los derechos fundamentales, por ejemplo, la disposición que prohíbe la valoración probatoria de elementos obtenidos de manera contraria a los derechos fundamentales (Tribunal Constitucional Federal, pp. 29-61). Además, se encuentra la reserva judicial, como requisito para procedimientos de investigación, que afectan sensiblemente los derechos fundamentales (Tribunal Constitucional Federal, t. 103, pp. 142-153).

De igual forma, es valiosa una dogmática constitucional de los derechos fundamentales aplicable y realizable, como se ha desarrollado y se desarrolla en el Tribunal Constitucional Federal. Las palabras clave que se pueden destacar para la libertad en la época del terrorismo son: reserva de ley parlamentaria, principio de prohibición de omisión (Untermaßverbot), protección de derechos fundamentales por el procedimiento, principio de proporcionalidad y deberes de protección de derechos fundamentales. A continuación quisiera destacar dos mecanismos, con el trasfondo de los peligros terroristas: los deberes estatales de protección de los derechos fundamentales y el principio de proporcionalidad.

\section{Deberes de protección}

En conjunto, las mencionadas decisiones del Tribunal Constitucional Federal muestran que las medidas que limitan potencialmente los derechos fundamentales para la lucha contra nuevas manifestaciones del terrorismo pueden ser supervisadas con la dogmática actual de los derechos fundamentales, en general, y con miras al caso concreto. El Tribunal Constitucional Federal niega, acertadamente, soluciones generales encaminadas a combatir el terrorismo "a cualquier precio". Especialmente ilustrativo se ve esto en la sentencia del Tribunal Constitucional Federal sobre la ley de seguridad aérea.

El 5 de enero de 2003, un hombre armado secuestró un avión, sobrevoló el distrito bancario de Francfort del Meno y amenazó con estrellar el avión contra la sede del Banco Central Europeo, si no se le posibilitaba una comunicación telefónica a Estados Unidos de América. Un helicóptero de la policía y dos cazarreactores de la Fuerza Aérea despegaron y rodearon la aeronave. La Policía desató una gran alarma: el centro de Francfort fue desalojado y los edificios fueron evacuados. Transcurrida media hora tras la captura del avión, era claro que se trataba de un hombre perturbado; una vez que fueron cumplidas sus exigencias, aterrizó en el aeropuerto Rhein-Main y permitió su arresto sin oponer resistencia (Tribunal Constitucional Federal, 15 de febrero de 2006, p. 751).

A causa de este suceso, junto con los atentados terroristas en el World Trade Center, el Bundestag expidió, el 11 de enero de 2005, la ley para la nueva regulación de las tareas de seguridad aérea 
(Boletín Oficial t. I, p. 78). Ésta permitía a las Fuerzas Armadas derribar una aeronave si está siendo utilizado para atentar contra vidas humanas, sobre todo, cuando el derribamiento es el único medio para la defensa contra este peligro inminente $(\S$ 14 párr. 3 Ley de seguridad aérea).

La normativa intervenía en el ámbito de protección del Derecho a la Vida de la tripulación y de los pasajeros del avión por derribar y, naturalmente, también en la de aquéllos que quieren utilizarlo para atentar contra la vida de otras personas, garantizado por el art. 2 párr. 2 frase 1 Ley Fundamental. Esta intervención debe estar justificada. Se puede intervenir, porque se encuentra bajo reserva de ley (art. 2 párr. 2 frase 3 Ley Fundamental). Una ley que intervenga este derecho tiene que ser formal y materialmente conforme a la Constitución. El Tribunal Constitucional Federal ya ha negado la competencia legislativa de la Federación, es decir, la conformidad formal con la Constitución (Tribunal Constitucional Federal, 15 de febrero de 2006, pp. 753 y ss.).

Por otro lado -y esto es importante para el tema de la libertad garantizada por los derechos fundamentales-, el Tribunal Constitucional Federal vio una infracción material contra el derecho a la vida (art. 2 párr. 2 frase $1 \mathrm{LF}$ ), en tanto que, el § 14 párr. 3 Ley de seguridad aérea, autorizaba el derribamiento de aviones en los que se encuentran personas que son víctimas de un ataque contra la seguridad del tráfico aéreo (Tribunal Constitucional Federal, 15 de febrero de 2006, pp. 757 y ss.), otro criterio se establece para aeronaves no tripuladas o tripuladas solamente por terroristas (pp. 760 y ss.).

Como motivo de la infracción de los derechos fundamentales, el Tribunal Constitucional Federal ha recurrido a su dogmática de los derechos fundamentales, según la cual, una ley que limite un derecho fundamental se debe interpretar a la luz del derecho que pretende ser limitado. Esta teoría de la interacción se ha extendido para el derecho a la vida, y con ello, también se ha relacionado estrechamente con la garantía de la Dignidad Humana del art. 1 párr. 1 LF (Tribunal Constitucional Federal, 15 de febrero de 2006, p. 757); igualmente, se ha unido con su dogmática de los deberes de protección (p. 757).

De la relación entre el Derecho a la Vida y la garantía de la Dignidad Humana, el tribunal deriva un deber del Estado y de sus órganos de situarse de manera protectora y favorecedora ante la vida de cada individuo; eso significa, primordialmente, protegerlos frente a intervenciones y ataques, por parte de terceros (Tribunal Constitucional Federal, 15 de febrero de 2006, p. 757; Tribunal Constitucional Federal, s.f., t. 39, pp. 1-42; t. 46, pp. 160-164; t. 56, pp. 54-73). Este deber de protección tiene su base en el art. 1 párr. 1 frase $2 \mathrm{LF}$, que obliga expresamente al Estado a respetar y proteger la dignidad humana (Tribunal Constitucional Federal, 15 de febrero de 2006, p. 757; Tribunal Constitucional Federal, s.f., t. 46, p. 164; t. 49, p. 142); t. 88, p. 251); esto excluye, completamente, utilizar a las personas como simples objetos del Estado (Tribunal Constitucional Federal, 15 de febrero de 2006, p. 757; Tribunal Constitucional Federal, s.f., t. 27 , p. 6 ; t. 45 , p. 228 ; t. 96 , p. 399 ).

La tripulación y los pasajeros de la aeronave convertida en arma no sólo son utilizados como objetos por parte de los secuestradores, sino también del Estado, que soluciona una situación con el derribamiento de la aeronave ( $\S 14$ Abs. 3 Ley de seguridad aérea) y trata a los pasajeros inocentes y a la tripulación como simples objetos de su acción de salvamento de otros (Tribunal Constitucional Federal, 15 de febrero de 2006, p. 758). En estas circunstancias, también es importante considerar que la decisión de derribamiento es tomada a contrareloj y bajo grandes factores de inseguridad, es decir, sin informaciones y pronósticos seguros (p. 758). 
Según la voluntad del Tribunal Constitucional Federal, esta dogmática de los deberes de protección sirve para complementar el carácter de los derechos fundamentales, como derechos de defensa contra el Estado, y para, de esta manera, fortalecer la protección de los titulares de derechos (Tribunal Constitucional Federal, s.f., t. 9, p. 41; t. 53, p. 57; t. 77, p. 214); en esto yace una ampliación del ámbito de los derechos fundamentales. En este sentido, sería contradictorio que se facilitara la justificación de intervenciones en los derechos fundamentales con la dogmática de los deberes de protección.

En todo caso, las intervenciones en los derechos fundamentales pueden estar justificadas por los derechos fundamentales de otras personas. Si se ampliara este motivo de justificación, con la ayuda de la dogmática de los deberes de protección, la protección de los derechos fundamentales terminaría en una simple ponderación de éstos, contrapuestos por causa de la reserva de ley por parte del legislador en ejercicio de su prerrogativa de valoración (Einschätzungsprärogative). Sin embargo, esto sería contradictorio con la vinculación inmediata del legislador a los derechos fundamentales dispuesta en el art. 1 párr. 3 LF y, además, debilitaría los derechos fundamentales, puesto que los convertiría -como en la época de Weimar- en simples frases programáticas. Por lo tanto, considero importantes las explicaciones del Tribunal Constitucional Federal en la sentencia de la ley de seguridad aérea, en las cuales el derribo de una aeronave, en la que se encuentran pasajeros inocentes, no se puede justificar con el deber estatal de protección de los derechos fundamentales de los que son amenazados en su derecho a la vida por el atentado planeado con el avión (Tribunal Constitucional Federal, 15 de febrero de 2006, p. 759).

De igual manera, quisiera añadir que una ley que declara como conforme a la constitución el dispararles a inocentes, les anularía a éstos su derecho a una legítima defensa, ya que contra un ataque conforme a la ley no existe tal derecho (definición de legítima defensa del § 32 párr. 2 Código Penal Alemán). Además, si se piensa que, probablemente, se tendrá que decidir a contrareloj y en circunstancias inseguras, el legislador no tiene permitido autorizar disparar contra los pasajeros; es más, tendría que prohibir completamente el tráfico aéreo. Los pasajeros de un avión secuestrado por terroristas no pueden ser sacrificados, ni siquiera si se tiene como objetivo impedir una tragedia mayor ni siquiera con la ayuda de la dogmática de la protección de derechos.

\section{Principio de proporcionalidad}

Ante todo, es necesario aclarar el significado de la dogmática de los derechos fundamentales para la libertad, garantizada por los derechos fundamentales en la época del terrorismo, con otro destacado instrumento de protección: el principio de proporcionalidad. Como ejemplo actual, pueden servir, en primer lugar, la sentencia sobre la ley de seguridad aérea y luego la decisión del Tribunal Constitucional Federal sobre la recopilación computarizada de datos personales.

Para el caso en que una aeronave sea convertida en arma, pero sólo sea ocupada por terroristas que quieren matar a personas en tierra, el Tribunal Constitucional Federal no considera, con razón, que si se derriba el avión exista una infracción contra la dignidad humana de los autores, de manera que la intervención en el derecho a la vida que implica la autorización legal para el derribamiento únicamente debe satisfacer las exigencias del principio de proporcionalidad. El Tribunal Constitucional Federal ha afirmado esto con un examen tradicional de proporcionalidad: el objetivo de la autorización legal, salvar vidas humanas, es legítimo en este caso (Tribunal Constitucional Federal, 15 de febrero de 2006, p. 760). La autorización es, en principio, apropiada para alcanzar el objetivo (p. 760), y es también necesaria, porque no es 
evidente otro medio igualmente efectivo que no intervenga, o que intervenga menos, en el derecho a la vida del autor (p. 761).

Finalmente, la autorización para la intervención es igualmente proporcionada en sentido estricto. El derribamiento de una aeronave, después de una ponderación completa, representa, ante el peso de los derechos que se protegen, una medida proporcionada y justa para el afectado, a pesar de la severidad de la intervención en los derechos fundamentales que conlleva (Tribunal Constitucional Federal, 15 de febrero de 2006, p. 761; Tribunal Constitucional Federal, s.f., t. 90, p. 173; t. 104, p. 349; t. 110, p. 165).

Me parece desafortunado -dogmáticamente hablando- que el Tribunal Constitucional Federal advierta otra vez sobre el deber del Estado de proteger a las víctimas inocentes, ya que esto no es realmente necesario en el marco del examen de proporcionalidad. Esto apoya la idea del peligro que existe de que una malentendida dogmática de los deberes de protección pueda disolver la vinculación inmediata a los derechos fundamentales.

En cuanto al gran significado del principio de proporcionalidad para la libertad garantizada por los derechos fundamentales en la época del terrorismo, se puede señalar el caso de la decisión del Tribunal Constitucional Federal del 4 de abril de $2006^{11}$ sobre la recopilación computarizada de datos personales. La recopilación computarizada de datos personales es un método policial de investigación, que consiste en el tratamiento automatizado de datos. Este método fue desarrollado en los años setenta y tenía como objetivo luchar contra el terrorismo teniendo, sin embargo, en ese entonces tuvo poco éxito ${ }^{12}$.

11 http://www.bverfg.de/ ( = en la revista NJW 2006, pp. 1939 y ss.).

12 http://www.bverfg.de/ (en este punto no publicado en la revista NJW 2006, pp. 1939 y ss.).
La Policía recibe de otras entidades públicas o privadas datos personales, a fin de efectuar una comparación electrónica (rasterung) con otros datos. Por medio de la comparación se debe investigar un número de personas, para las cuales son aplicables ciertos criterios, que son vistos como significativos para otras investigaciones. Hoy en día, este método no sólo está previsto para la persecución penal (§ 98a Código de Procedimiento Penal), sino también como instrumento preventivo (fahndungsinstrument) en las leyes de policía de la mayoría de los Estados Federados (§ 40 PolizeiG B.-W.).

Con una recopilación computarizada de datos personales deben ser reconocidos los llamados "durmientes", es decir, aquellas personas que están preparadas para actividades terroristas, pero que por largo tiempo se esfuerzan cuidadosamente por comportarse de acuerdo con la Ley y así pasar desapercibidos, para poder llevar a cabo sus planes criminales en un momento decisivo y, con eso, poder actuar con mayor efectividad.

A causa de un precepto de la ley de policía de Renania del Norte-Palatinado (Boletín Oficial del estado federado de Reanania del Norte-Palatinado, 1990, p. 70), que establece una reserva judicial para una recopilación computarizada de datos personales, se expidió una orden judicial en octubre de 2001 para la ejecución de una recopilación. Con ella se debían reconocer personas, que siendo miembros o simpatizantes de organizaciones terroristas, estuvieran preparadas para realizar atentados terroristas; finalmente, $\mathbf{1 1 . 0 0 0}$ personas fueron informadas de que sus datos iban investigados. En consecuencia, un ciudadano marroquí, estudiante de la Universidad de Duisburg, interpuso una acción contra la decisión judicial que autorizaba la recopilación. La queja fue negada por el tribunal de primera instancia y por el tribunal superior. Su recurso de amparo subsiguiente tuvo éxito ante el Tribunal Constitucional Federal. 
El Tribunal Constitucional Federal recurrió al derecho a la autodeterminación informativa como medida de examen. Reiteró y precisó el alcance de su ámbito de protección descrito en la sentencia del censo de la población y en sentencias posteriores. Este derecho fundamental protege de actividades de observación y vigilancia de la policía, en lo que se refiera a datos personales, como el nombre, el domicilio, el lugar y la fecha de nacimiento, la nacionalidad, la religión o la orientación de los estudios (Tribunal Constitucional Federal, 4 de abril de 2006, pp. 1940 y ss.).

La ley que autoriza la recopilación computarizada de datos personales y la recopilación ordenada interviene en el ámbito de protección del derecho a la autodeterminación informativa del demandante (art. 2 párr. 1 en conexión con el art. 1 párr. 1 LF); en el caso mencionado de la recopilación computarizada, en el mismo derecho de por lo menos 11.000 personas. Para esto, el Tribunal Constitucional Federal interpretó ampliamente el concepto de intervención; la calidad de intervención sólo se puede negar si son abarcados datos de manera no dirigida y solamente es determinada por medios técnicos, que sean separados inmediatamente después de la obtención, técnica y anónimamente, sin dejar huella y sin interés de reconocimiento para la autoridad (Tribunal Constitucional Federal, 4 de abril de 2006, p. 1939; BVerfGE, 100, 313 [366]; 107, 299 [328]).

Cuando la obtención de una gran reserva de datos solamente es un medio para reducir la cantidad de resultados obtenidos, la recolección de datos se puede considerar como una intervención (Tribunal Constitucional Federal, 4 de abril de 2006, p. 1941; BVerfGE, s.f., t. 100, pp. 336 y 380). Asimismo, en el almacenamiento -incluso si sólo es provisional- de los datos por parte del organismo que los transmite, conservada y pone a disposición para la comparación, interviene en el derecho a la autodeterminación informativa de las personas que van a ser objeto de otras medidas tras la comparación de los datos (Tribunal Constitucional
Federal, 4 de abril de 2006, pp. 1939-1941; BVerfGE, s.f., t. 100, p. 366). Finalmente, la comparación de los datos también tiene carácter de intervención con respecto a esas personas, porque es un acto para elegir personas para una valoración posterior (Tribunal Constitucional Federal, 4 de abril de 2006, p. 1941; BVerfGE, s.f., t. 100, p. 366).

Tal intervención, a través de un acto individual, sólo puede estar justificada constitucionalmente y si está cubierta por un límite del derecho fundamental. Para que eso suceda, las bases jurídicas de intervención (EGL) tienen que ser formal y materialmente conformes con la Constitución. Como medida de examen decisiva para la autorización legal y para la disposición judicial, el Tribunal Constitucional Federal utilizó respectivamente el principio de proporcionalidad. Por lo tanto, efectuó un examen doble de proporcionalidad en las intervenciones por actos individuales; el primero, con respecto a la ley, confirmó la proporcionalidad de la autorización legal, sin embargo, en el segundo momento, relativo al acto individual de la disposición de recopilación, condujo al éxito del recurso de amparo constitucional. Con este doble examen de proporcionalidad no sólo se alcanzó una protección doble del afectado, sino que también fue contrarrestado tempranamente, y a pesar de las situaciones de amenaza terrorista, el desarrollo de un Estado de vigilancia.

Para la constitucionalidad de la recopilación computarizada de datos personales, el Tribunal Constitucional exige al legislador, como requisito para la disposición de una recopilación computarizada de un caso concreto, que establezca una amenaza concreta de terrorismo. Así el Tribunal Constitucional Federal limita la prerrogativa de valoración del legislador a través de la exigencia típica (tatbestandserfordernis) de un peligro concreto, como requisito que asegura los derechos fundamentales. En esa medida, el Tribunal Constitucional Federal aumenta la densidad del control, porque no sólo 
le obliga a la Administración a examinar la existencia de una situación de peligro terrorista, sino que también -en un nivel anterior- el legislador le deja la competencia a la Administración para realizar una recopilación computarizada sólo cuando existe un peligro concreto.

El Tribunal Constitucional Federal tiene razones a favor para proceder de esta manera, sobre todo, cuando una intervención por medio de una recopilación computarizada de datos personales es de la alta intensidad; esta intensidad se fundamenta en la cantidad de datos recolectados y el elevado riesgo que pueden tener los investigados de ser objetivo de otras investigaciones, por parte de las autoridades. Una de las razones del Tribunal tiene que ver con la estigmatización a los que cumplen las características de la recopilación, así como con la clandestinidad de la recopilación, el peligro de que la identidad de la persona no permanezca anónima; en últimas, el Tribunal pretende es que la recopilación computarizada sea una intervención sin sospecha, con una gran extensión (Tribunal Constitucional Federal, 4 de abril de 2006, p. 1943) ${ }^{13}$.

Generalizando, de la recopilación computarizada de datos personales se puede concluir que el Tribunal Constitucional Federal contrarresta fuertemente una legislación de seguridad con la exigencia de un proceder cuidadoso. Asimismo, para el Tribunal son intentos legislativos demasiado agudos, que son considerados muy extensos y, por lo tanto, incorrectos.

Como ejemplos adicionales se deben nombrar, junto con la sentencia sobre la ley de seguridad aérea, las decisiones sobre la orden de arresto europea (BVerfGE, s.f., t. 113, pp. 273 y ss.) y sobre la vigilancia secreta a gran escala (t. 109, pp. 279 y ss.).

$13 \quad$ Hay varias críticas al respecto; por ejemplo: la opinión disidente de la magistrada del Tribunal Constitucional Federal Evelyn Haas, así como los comentarios a la sentencia de Winfried Bausback (2006, pp. 1922 y ss.) y de Uwe Volkmann (2006, p. 919 y ss.).
Un ejemplo de esto es el caso de una extradición a cualquier precio -especialmente sin una posibilidad efectiva de protección jurídica-, que fue negada, así como que una vigilancia acústica ilimitada de viviendas. Con esto, el Tribunal Constitucional Federal obligó al legislador a realizar correcciones, por lo que le dio directrices que le permitieran aprender continuamente, en el sentido de ensayo-error.

Entre estas directivas de lucha contra el terrorismo conforme a la Constitución, se encuentran las cuatro siguientes:

- Las exigencias para la justificación de una ley son más rigurosas en relación con la amplitud que tenga la intervención prevista en la ley.

- Son significativas para la justificación de una intervención su clase y manera. Por ejemplo, si la intervención es secreta, aumentan las exigencias para la justificación.

- Una ley que promueva la seguridad debe contener mecanismos de compensación que reduzcan la intensidad de la intervención. Uno de estos mecanismos podría ser la reserva judicial, como en el caso de la vigilancia a gran escala y de la recopilación computarizada de datos personales. Además, el aviso a los afectados -por ejemplo, en el caso de la recopilación computarizada de datos- o una prohibición de valoración probatoria -como en el caso de la vigilancia de viviendas a gran escala- pueden atenuar la intensidad de la intervención.

- Los afectados tienen que poder obtener protección jurídica, tanto contra el acto individual (BVerfGE, s.f., t. 113, pp. 310-314 y ss.) como contra la autorización legal (t., pp. 362, 384 y ss.). Recientemente, el Tribunal Constitucional Federal, en la decisión sobre la constitucionalidad de la utilización de IMSI-Catchers del 22 de agosto de 2006, realzó en un obiter dictum que las precauciones procesales -como los deberes de información o las posibilidades de 
protección jurídica- son necesarias para garantizar la efectiva protección de los derechos fundamentales (Tribunal Constitucional Federal, 22 de agosto de 2006).

Adicionalmente, se puede aferrar a las acreditadas directrices de la dogmática de los derechos fundamentales, que sirven para asegurar la libertad garantizada por los derechos fundamentales en la época del terrorismo:

- El examen tradicional de los derechos fundamentales en la forma de tres pasos (ámbito de protección, intervención y justificación de la intervención) lleva, en caso de duda, a que los menoscabos de los derechos fundamentales puedan ser sometidos a un control de justificación claramente estructurado y que apoye la libertad (Ibler, s.f., art. 19, marg. 17).

- Este aspecto de apoyo a la libertad del examen en tres etapas de los derechos fundamentales se fortalece más si se siguen otras reglas dogmáticas, en las cuales, en caso de duda, se debe interpretar con amplitud el ámbito de protección de un derecho fundamental, como, por ejemplo, sucedió en la decisión sobre la recopilación computarizada de datos personales (Tribunal Constitucional Federal, 4 de abril de 2006, p. 1941). Así, se impide excluir de antemano actos estatales potencialmente limitadores de la libertad, de un control en la medida del ámbito de protección de los derechos fundamentales.

- A lo anterior corresponde la siguiente regla: en caso de duda se debe de interpretar el concepto de intervención de manera amplia; en este caso también se puede poner como ejemplo la decisión sobre la recopilación computarizada de datos personales.

- Con la amplia interpretación del ámbito de protección y del concepto de intervención se logra examinar muchas medidas estatales, es decir, se logra examinar si existen razones constitucionales que justifiquen la limitación la libertad protegida por el respectivo derecho. Como se mostró con el ejemplo de la sentencia del Tribunal Constitucional Federal sobre la ley de seguridad aérea, iría en contra del significado de los derechos fundamentales como derechos de vinculación inmediata, elaborar nuevas razones de justificación para las intervenciones estatales con ayuda de la dogmática de los deberes de protección.

- Naturalmente, esta dogmática de los derechos fundamentales ha obtenido eficacia (schlagkraft) para la protección de la libertad garantizada por los derechos fundamentales, naturalmente por la existencia del Tribunal Constitucional Federal y su posición sumamente fuerte como tribunal y como órgano constitucional. Esta posición le hace posible anular decisiones de otros tribunales, aun de los tribunales federales y de leyes (BVerfGG, s.f., §§ 78, 95 párr. 2 y 3). La protección de la libertad garantizada por los derechos fundamentales que es alcanzada por la fuerte posición del Tribunal Constitucional Federal se materializa justamente en el marco del examen de justificación para el cual el Tribunal Constitucional Federal, con una jurisprudencia de décadas, ha precisado y perfeccionado una medida como el principio de proporcionalidad. Con este principio se puede proteger suficientemente la libertad garantizada por los derechos fundamentales, ante los nuevos retos del terrorismo, y se puede limitar de manera verificable, como lo exige la Constitución para garantizar una protección necesaria contra atentados terroristas criminales.

\section{OBSERVACIONES DE RESUMEN $Y$ CONCLUSIÓN}

Para concluir, se debe retener que se pueden enfrentar nuevas amenazas para la libertad garantizada por los derechos fundamentales, mientras el sistema de la Ley Fundamental para la protección 
de la libertad garantizada por los derechos fundamentales funcione. En ese sentido, una prueba de su eficacia es la Ley Fundamental de 1949, la cual no ha construido la protección de los derechos fundamentales para permanecer invariable en el futuro. Por el contrario, aunque el constituyente de entonces pudo fijar sólo un estándar mínimo. La Ley Fundamental posibilitó una protección móvil -con límites- de los derechos fundamentales. Así, se permiten modificaciones del texto constitucional ${ }^{14}$ sencillamente, y esta posibilidad ha sido utilizada por el constituyente de manera ${ }^{15}$ frecuente. Por ejemplo, con la constitución de estados de excepción (art. 115a - 115l LF), con el secreto en las telecomunicaciones (art. 10 párr. $1 \mathrm{LF),} \mathrm{las} \mathrm{modificaciones}$ en cuanto a la inviolabilidad del domicilio (art. 13 LF) y con el derecho de asilo (art. 16 LF).

Para algunos derechos fundamentales es incluso permitido que el legislador contribuya a su configuración, si el derecho fundamental junto a su función de derecho de defensa, también contiene una Garantía Institucional, como los derechos fundamentales al matrimonio y a la familia, a la propiedad y a la herencia (erbrecht), y a la protección jurídica efectiva. Ya se ha mencionado la competencia del Tribunal Constitucional Federal para la precisión de los ámbitos de los derechos fundamentales, parcialmente a través de una interpretación creadora de Derecho, desde la perspectiva del derecho a la autodeterminación informativa, con la indicación sobre la decisión sobre la recopilación computarizada de datos personales y sobre la sentencia del censo de la población. La fuerza de la protección de los derechos fundamentales se basa en que los derechos fundamentales no son garantizados ilimitadamente. Más bien, la Constitución admite -a pesar de la fuerza vinculante inmediata de los derechos fundamentales-, a

14 En comparción con la Constitución Española de 1978 (Ibler, 1999, pp. 290 y s.).

15 En España sólo existe una modificación a la Constitución de 1978, véase modificación del 27 de agosto de 1992, Boletín Oficial (28 de agosto de 1992) (Introducción del Derecho de participación en las elecciones municipales para ciudadanos de la Unión Europea). través de la reserva de ley y de límites inmanentesintervenciones en los derechos fundamentales, que requieren justificación y que pueden ser controladas por el Tribunal Constitucional Federal.

\section{BIBLIOGRAFÍA}

Anderson, John R. (2000) Learning and Memory ( $2^{\mathrm{a}}$ edición).

Atkinson, Rita L., Atkinson, Richard C., Smith, Edgard E. Bem, Daryl J. (1990) Introduction to Psychology (10 $10^{\mathrm{a}}$ edición).

Bausback, Winfried. (2006) Neue Juristische Wochenschrift, pp. 1922 y ss.

Bausback, Winfried. (Sin fecha) Terrorismusabwehr durch gezielte Tötungen? - Assassination als Mittel des (deutschen) demokratischen Rechtsstaates? Neue Zeitschrift für Verwaltungsrecht, 418 y ss.

Buggisch, Walter und Knorz, Walter. (2006) Terrorismusbekämpfung einmal anders. Die AG BIRGiT und das Ausländerrecht als Instrument zur Bekämpfung des islamischen Terrorismus und Extremismus. Kriminalistik, 226 y ss.

Bundestags-Drucksache (16 de octubre de 2006).

Bundestags-Drucksache (29 de noviembre de 2006).

Bung, Jochen. (2006) Feindstrafrecht als Theorie der Normgeltung und der Person. Höchstrichterliche Rechtsprechung Strafrecht, 63 y ss.

BVerfGE. (Sin fecha). Tomos: 39, 53, 65, 77, 80, 100, 103, 107, 109, 113.

BVerfGG. (Sin fecha) Ley del Tribunal Federal Constitucional, antigua versión, eliminado por la Ley para la reforma de la BVerfGG del 21 de julio de 1956. Boletín Oficial de la República Federal (tomo I). 
Callies, Christian. (2002) Sicherheit im freiheitlichen Rechtsstaat - Eine verfassungsrechtliche Gratwanderung mit staatstheoretischem Kompass. Zeitschrift für Rechtspolitik.

Callies, Christian. (2006) Die grundrechtliche Schutzpflicht im mehrpoligen Verfassungsrechtsverhältnis. Juristenzeitung, 321-325.

Christen, Karina. (19 de octubre de 2006) Die unglaubliche Geschichte des Murat Kurnaz. Südkurier, 242, 3.

Diwell, Lutz. (2005) Aufgabenverbund von Polizei und Geheimdiensten bei der Bekämpfung des islamistischen Terrorismus. En Schreckenberger (Hrsg.). Speyerer Arbeitsheft, 175, 11 y ss.

Frankfurter Allgemeine Zeitung (21 de octubre de 2006), 295.

Frankfurter Allgemeine, (23 de octubre de 2006) 246, 11.

Gesetz zur Regelung des Zugangs zu Informationen des Bundes (Informationsfreiheitsgesetz IFG) (tomo I, p. 2722). (5 de septiembre de 2005). Bundesgesetzblatt (BGBI.) (Boletín oficial de la República Federal).

Götz, Volkmar. (2001) Allgemeines Polizei- und Ordnungsrecht (13 ${ }^{\text {a }}$ edición, número marginal 533 ).

Hetzer, Wolfgang. (2006) Verschleppung und Folter. Staatsraison oder Regierungskriminalität? Kriminalistik, pp. 148 y ss.

Ibler, Martin. (1999) Der Grundrechtsschutz in der spanischen Verfassung am Beispiel des Eigentums. Juristenzeitung, 287 y ss.

Ibler, Martin. (2002) Zerstören die neuen Informationszugangsgesetze die Dogmatik des deutschen
Verwaltungsrechts? (pp. 405 y ss.). En Festschrift für Winfried Brohm.

Ibler, Martin. (2002). In Friauf Höfling. Berliner Kommentar zum Grundgesetz, Art. 19 IV núm. marg. 17.

Informationen_zum_Terrorismusaenderungsgesetz.pdf.

Introducción del Derecho de participación en las elecciones municipales para ciudadanos de la Unión Europeo (28 de agosto de 1992). Boletín Oficial, 207.

Jakobs, Günther. (2004) Bürgerstrafrecht und Feindstrafrecht. Höchstrichterliche Rechtsprechung Strafrecht, 88 y ss.

Jakobs, Michael Ch. (2006) Terrorismus und polizeilicher Todesschuss. Deutsches Verwaltungsblatt, 83 y ss.

Kubica, Johann. (2006) Neuorganisation im Bundeskriminalamt bei der internationalen Zusammenarbeit. Kriminalistik, 167 y ss.

Pestalozza, Christian. (1991) Verfassungsprozessrecht ( $3^{\mathrm{a}}$ edición).

Roellecke, Gerd. (2006) Der Rechtsstaat im Kampf gegen den Terror. Juristenzeitung, 265-268.

Sağlam, Fazil. (2006) Die Türkei auf dem Weg zum Rechtsstaat - Stand und praktische Umsetzung der Reformen. En: Bitburger Gespräche, Jahrbuch, 179-198.

Schmidt, Carmen. (2006). En la revista Monatshefte für Osteuropäisches Recht, 163 y ss.

Sinn, Arndt. (2006) Moderne Verbrechensverfolgung - auf dem Weg zu einem Feindstrafrecht? 
Zeitschrift für Internationale Strafrechtsdogmatik, 107 y ss.

Süddeutsche Zeitung (31 de agosto de 2007), 200.

Terrorangst am Busbahnhof. (25 de octubre de 2006) Südkurier, 247, 1-27.

Timm, Klaus Jürgen. (2006) Polizeiliche Gefahrenabwehr oder Landesverteidigung? Kriminalistik, 146 y ss.

Tribunal Constitucional Federal. ( 15 de febrero de 2006). En la revista Neue Juristische Wochenschrift. Recuperado en: http://www.bverfg.de/.

Tribunal Constitucional Federal. (22 de agosto de 2006).

Tribunal Constitucional Federal. (4 de abril de 2006). En la revista Neue Juristische Wochenschrift. Recuperado en: http://www.bverfg.de.

Tribunal Constitucional Federal. (2 de marzo de 2006). En la revista Neue Juristische Wochenschrift. Recuperado en: http://www.bverfg.
Volkmann, Uwe. (2006) Juristenzeitung, 918 y ss.

Wiefelspütz, Dieter. (2006) Bundeswehr und innere Sicherheit. Nordrhein-Westfälische Verwaltungsblätter, 41-42.

Wittinger, Michaela (2006) In der Nachbarschaft von Botschaften und Konsulaten: kann das Baurecht vor den Gefahren des Terrorismus schützen? Deutsches Verwaltungsblatt, pp. 17y ss.

Wolfgang, Hetzer. (2005) Terrorabwehr im Rechtsstaat. Zeitschrift für Rechtspolitik, p.132.

Würtenberger, Thomas und Heckmann, Dirk. (2005) Polizeirecht in Baden-Württemberg ( $6^{\mathrm{a}} \mathrm{ed}$ ición, número marginal 671).

http://www.bmi.bund.de/Internet/Content/Common/Anlagen/Nachrichten/ Pressemitteilungen/2006/ 07/Informatioen zum_Terrorismusaenderungsgesetz,templateld =raw, property=publicationFile.pdf/

http://www.bverfg.de/ 